\title{
Evaporation and Evaluation of Seven Estimation Methods: Results from Brullus Lake, North of Nile Delta, Egypt
}

\author{
Maged Mohamed Abdel Moneim Hussein \\ Marine Physics Laboratory, Division of Marine Environment, National Institute of Oceanography and Fisheries (NIOF), Alexandria, Egypt
}

\section{Email address:}

maged_hussain1@yahoo.com

\section{To cite this article:}

Maged Mohamed Abdel Moneim Hussein. Evaporation and Evaluation of Seven Estimation Methods: Results from Brullus Lake, North of Nile Delta, Egypt. Hydrology. Vol. 5, No. 4, 2017, pp. 58-66. doi: 10.11648/j.hyd.20170504.12

Received: February 3, 2017; Accepted: February 28, 2017; Published: October 22, 2017

\begin{abstract}
Variations in lake evaporation have a significant impact on the energy budget and water budget of lake. Understanding these variations and the role of climate is important for water resource management as well as predicting future changes in Lake Hydrology as a result of climate change. This study presents a comprehensive of 10 years dataset (2003 2012) from Lake Brullus (Nile Delta Lake) North-Egypt for monthly and annually variations in lake evaporation. Evaporation during this interval was calculated using six evaporation methods, based on field meteorology, and lake water temperature data. Actual evaporation determined during a month of a year was estimated using a lake energy budget model, and the estimation was used as reference evaporation for evaluation of the six methods. The deviations of method carried out evaporation results from the reference evaporation were compared among the six methods, and an execution rank was suggested based on the root mean squared deviation and coefficient of efficiency. Makkink method was the best method for the whole data interval, followed by DeBruin-Kejiman method and the poor one is Penman method.
\end{abstract}

Keywords: Lake Brullus, Evaporation, Energy Budget, Temperature

\section{Introduction}

Accurate estimates of lake evaporation are necessary for water and energy budget studies, lake level forecasts, water quality surveys, water management and planning of hydraulic constructions. Evaporation process depends on the availability of thermal energy and the vapor pressure deficit between the evaporating surface and the overlying air, which in turn depend on meteorological factors such as solar radiation, temperature, relative humidity and wind velocity. Besides climate, lake characteristics as its size, shape, depth, water quality and circulation, even its location can affect the rate of evaporation. Thus, the estimation or measurement of the evaporation over a lake is a very difficult task, for which a multitude of methods exist, which can be classified into several categories including: 1) water budget, 2) measurement, like evaporation pans and eddy correlation technique, 3) energy budget, 4) mass transfer and 5) combination methods. The energy budget and eddy correlation techniques are regarded as the most accurate methods. As eddy correlation method is only suitable for short-term studies, the energy budget is the preferred technique for accurate, long-term monitoring $[6,11,15,20$, 22, 24, 28 and 34].

Several attempts have been made to estimate evaporation from different zones of the Mediterranean Sea using different techniques [24]. Nielsen, [18] reported evaporation as 175 $\mathrm{cm} /$ year. Schott, [26] computed evaporation (187 cm/year) by means of heat balance equations. Sverdrup [29] and Wust [36] calculated evaporation from the surface waters of the Mediterranean Sea as $145 \mathrm{~cm} /$ year. The annual evaporation value determined by Carter [9] was $115 \mathrm{~cm} /$ year, with minimum value $(4 \mathrm{~cm})$ in February and a maximum one (16 $\mathrm{cm})$ in August. On the basis of observations over the sea during the period 1924-1932, Tixeront [30] found that the average evaporation from the Mediterranean Sea amounted to $120 \mathrm{~cm} /$ year and Said, [23] computed evaporation (151.5 $\mathrm{cm} /$ year). Anonymous [5] represents that during Long-term averages ( $>20$ years) of the climatic records of two stations within Brullus Wetland the evaporation rate is between 3.3 to $5.6 \mathrm{~mm} / \mathrm{d}$. Hussain [14] calculated evaporation from Lake Brullus as $129.42 \mathrm{~cm} /$ year in 1988 and $138.6 \mathrm{~cm} /$ year in 1989 using aerodynamic method [4]. The evaporation from Lake Brullus has been estimated by Said and Hussein [24] as 
$157.79 \mathrm{~cm} /$ year in 2001 and $147.74 \mathrm{~cm} /$ year in 2002 .

The present study has two goals: 1) provide an evaporation study using 10 years datasets obtained for Lake Brullus located in the Egyptian coastal zone using six methods; and 2) compare deviations of method-calculated evaporation to the energy budget estimated evaporation, and identify the better methods for estimating lake evaporation for the region.

\section{Study Area Description}

Brullus Lake is located along the Mediterranean Deltaic coast. It lies at a central position between the two branches of Nile: Damietta to the east and Rosetta to the west. Its coordinates are $31^{\circ} 36^{\prime} \mathrm{N}$ and $30^{\circ} 33^{\prime} \mathrm{E}$ in north - west, $31^{\circ}$ $36^{\prime} \mathrm{N}$ and $31^{\circ} 07^{\prime} \mathrm{E}$ in the north - east, $31^{\circ} 22^{\prime} \mathrm{N}$ and $30^{\circ} 33^{\prime}$ $\mathrm{E}$ in the south - east, $31^{\circ} 22^{\prime} \mathrm{N}$ and $31^{\circ} 07^{\prime} \mathrm{E}$ in the south - east. It has a total area of $460 \mathrm{~km}^{2}$, which includes the entire area of Lake Brullus with a shoreline of about $65 \mathrm{~km}$ Figure $1[3]$.

According to the map of the world distribution of arid regions (UNESCO, 1977), the northern Mediterranean part of the Nile Delta belongs to the arid region. The climatic conditions are warm summer $\left(20^{\circ}\right.$ to $\left.30^{\circ} \mathrm{C}\right)$ and mild winter $\left(10^{\circ}\right.$ to $\left.20^{\circ} \mathrm{C}\right)[3]$.

The lake is roughly rectangular in shape, $60-70 \mathrm{~km}$ in length and $6-16 \mathrm{~km}$ with an average width $11 \mathrm{~km}$. The depth of the lake varies from $0.42 \mathrm{~cm} 2.07 \mathrm{~cm}$ with an average depth of $1 \mathrm{~m}$. the lake is connected to the Mediterranean Sea through Boughaz El-Brullus; of about 200m width and a maximum depth of $2.8 \mathrm{~m}$. It receives a huge amount of brackish water from five main drains per year [24, 25].

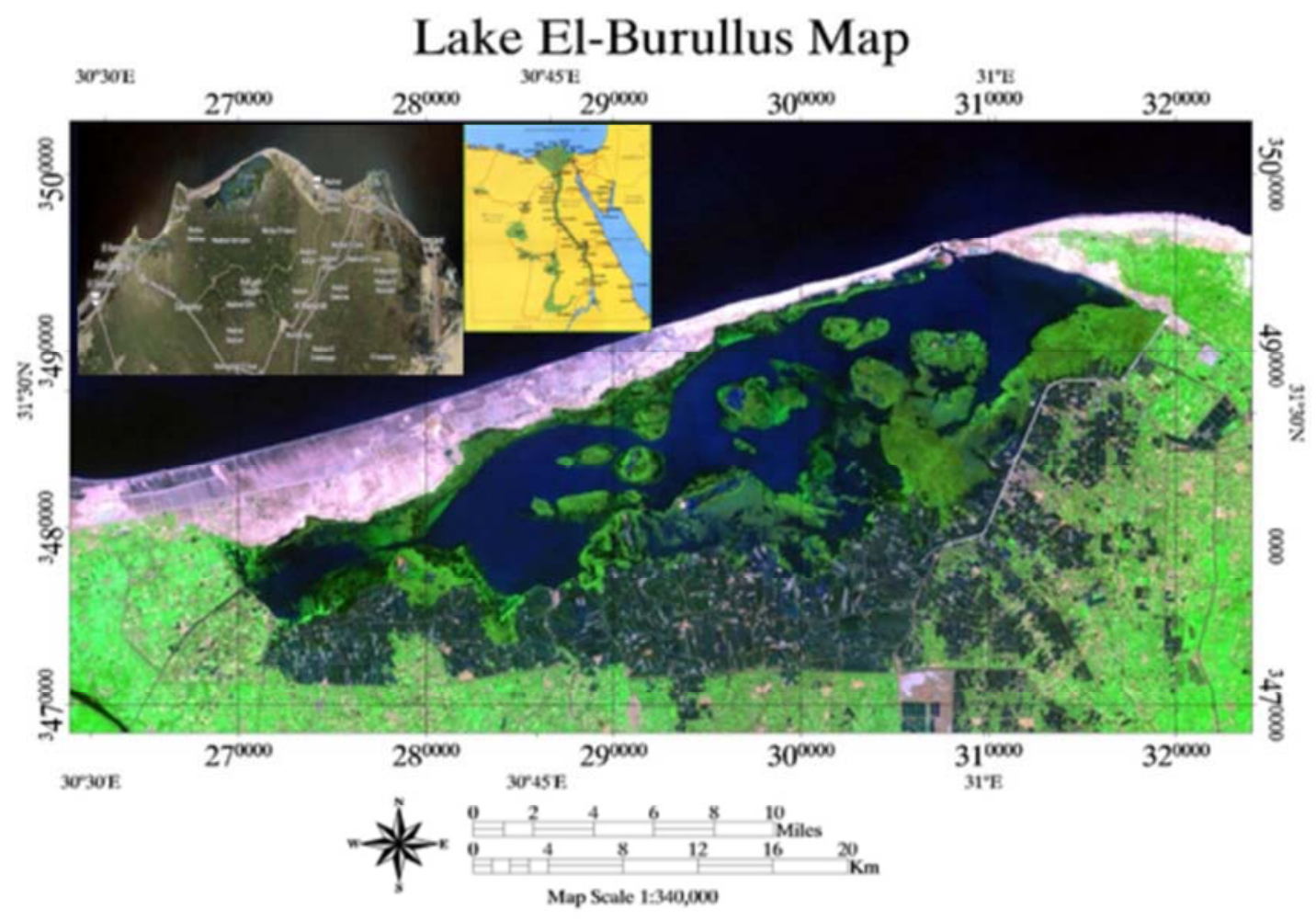

Figure 1. Lake Brullus study area [1].

\section{Materials and Methods Calculation}

The data used for calculations include daily mean air temperature, relative humidity, and wind speed. The processed data are available for the period of 10 years (20032012) and obtained from meteorology station located at the eastern part of Lake Brullus. Lake water temperature was measured monthly at multiple stations covering the lake area during the study period. Six methods are selected for calculation of evaporation from Lake Brullus and later compared to each other. They are Hamon (HM), Penman (PM), Priestley-Taylor (PT), DeBruin-Kejiman (DK), JensenHaise (JH), and Makkink (MK). Finally, Energy budget was calculated and has been taken as an evaporation reference of the study area.

\subsection{Hamon (HM) Method}

Yao and Creed [38] estimated the daily evaporation E $(\mathrm{mm})$ from daily air temperature $\mathrm{T}_{\mathrm{a}}\left({ }^{\circ} \mathrm{C}\right)$ as follows:

$$
E=0.63 D^{2} 10^{\frac{7.5 T_{a}}{T_{a}+273}}
$$

Where, $D$ is the ratio of maximum sunshine duration (hour) to 12 hours, and is determined by latitude of the lake and the date:

$$
D=\frac{1}{90} \arccos \left\{-\tan (\phi) \tan \left[23.45^{\circ} \sin \left(\frac{J-80}{365}\right) 360^{\circ}\right]\right\}
$$


Where $\varphi$ is the latitude, $\mathrm{J}$ is the Julian day of any date of interest.

\subsection{Penman (PM) Method}

A format of Penman equation, once recommended by Food and Agriculture Organization [2, 13], is used and slightly modified to calculate lake evaporation. The modification is an addition of the lake heat storage change rather than taking only the net radiation. The evaporation is written as:

$$
E=\frac{\Delta}{\Delta+\gamma} \frac{R_{n e t}-S}{\lambda}+\frac{\gamma}{\Delta+\gamma} 0.0026(1+0.54 \bar{u})(1-r) e_{s a} n
$$

where $R_{\text {net }}$ and $S$ are the net radiation (Joule) and lake heat storage change in the interval, $\lambda$ is the latent heat of vaporization $\left(2.46 \times 10^{6} \mathrm{~J} \mathrm{~kg}^{-1}\right), \bar{u}$ is the mean daily wind speed $\left(\mathrm{m} \mathrm{s}^{-1}\right)$ for the period, $r$ is the mean daily relative humidity $(\leq 1.0)$, $\mathrm{e}_{\mathrm{sa}}$ is the mean daily saturated vapor pressure $(\mathrm{Pa}), \Delta$ is the mean slope of the saturated vapor pressure-temperature curve at the air temperature, and $n$ is number of days in the interval. The two terms related to the slope $\Delta$ and psychrometric constant $\gamma$ are expressed as empirical relations of air temperature [39]:

$$
\frac{\Delta}{\Delta+\gamma}=0.439+0.01124 T_{a} \frac{\gamma}{\Delta+\gamma}=0.5495-0.01119 T_{a}
$$

The saturated vapor pressure is calculated with the Arden Buck Formula [27]:

$$
e_{s a}=611.21 \exp \left[\frac{\left(18.678-T_{a} / 234.5\right) T_{a}}{257.14+T_{a}}\right]
$$

The net radiation $\left(\mathrm{R}_{\text {net }}\right)\left(\mathrm{MJ} \mathrm{\textrm {m } ^ { - 2 }}\right.$ day $\left.^{-1}\right)$ is the difference between the incoming net shortwave radiation $\left(\mathrm{R}_{\mathrm{ns}}\right)$ and the outgoing net long-wave radiation $\left(\mathrm{R}_{\mathrm{nl}}\right)[31,32]$ :

$$
R_{n e t}=R_{n s}-R_{n l}
$$

According to [24] the energy that is taken up by the water body during the warmer months and subsequently released as evaporation during the cooler months by change in water heat storage from one month to the next. The mean monthly water body temperature, $\mathrm{T}_{\mathrm{wb}}$ defines as the arithmetic mean of epilimnion temperature (taken as water surface temperature, $\mathrm{T}_{\mathrm{w}}$ ) and the hypolimnion temperature, $\mathrm{T}_{\mathrm{b}}$ (Lake Bottom temperature). This assumes that in shallow lakes, the water volumes of the epilimnion and hypolimnion are equal, an as assumption that is not general true. Note, that lake heat gains and losses are primarily surface phenomena. Accordingly, as a first approximation, the change in hypolimnion temperature between one month and the next to be the same as that of the epilimnion when $T_{w}>T_{b}$ for shallow lake and negligible for deep lakes $\left(T_{b}\right.$ weakly varying), and computed the mean water body temperature change between month $\mathrm{j}$ and $\mathrm{j}-1$ from:

$$
\Delta T_{w b}=T_{w, j}-T_{w, j-1}
$$

Which is valid when $T_{w}=T_{b}$. The corresponding change in the heat storage from month $\mathrm{j}-1$ to $\mathrm{j}$ per unit area can then be computed by [33]:

$$
S=C \rho^{*} \rho^{*} h \Delta T_{w b} / n
$$

Where, $\mathrm{C} \rho=4186\left(\mathrm{~J} \mathrm{~kg}^{-1} \mathrm{C}^{-1}\right)$ is specific heat of water, $\rho=$ $1000\left(\mathrm{~kg} \mathrm{~m}^{-3}\right)$ is water density, $\mathrm{h}$ is the mean depth of lake (1 $\mathrm{m})$ and $\mathrm{n}$ is number of days in month.

\subsection{Priestley-Taylor (PT) Method}

Evaporation is estimated based on radiation and heat storage only, as done by Winter et al. [35]:

$$
E=1.26 \frac{\Delta}{\Delta+\gamma} \frac{R_{n e t}-S}{\lambda}
$$

\subsection{De Bruin-Kejiman (DK) Method}

The De Bruin-Kejiman equation is written as $[35,12]$.

$$
E=\frac{\Delta}{0.95 \Delta+0.63 \gamma} \frac{R_{n e t}-S}{\lambda}
$$

\subsection{Jensen-Haise Method}

Daily evaporation is calculated by the Equation given by Winter et al., [16, 19, and 35].

$$
E=\left[0.014\left(1.8 T_{a}+32\right)-0.5\right] \frac{R n s}{\lambda}
$$

\subsection{Makkink (MK) Method}

Daily evaporation is calculated as Winter et al. [16, 19, and 35]

$$
E=0.61 \frac{\Delta}{\Delta+\gamma} \frac{R n s}{\lambda}-0.012
$$

\subsection{Reference Evaporation Derived by Energy Budget}

The energy budget is often used for lake evaporation calculations [7, 15, 34, and 37]. For Lake Brullus and for a given time period previously defined, its energy budget is written as:

$$
\lambda E=R_{n e t}+H_{\text {sed }}+A_{\text {net }}-H-S
$$

Where, $\lambda \mathrm{E}$ is latent heat energy used by evaporation of lake water during the interval, $\mathrm{H}_{\text {sed }}$ is heat released by lake sediments and is negligible for most cases, $\mathrm{A}_{\text {net }}$ is net heat advected into the lake from precipitation, inflows and outflows, and is also negligible [37], $\mathrm{H}$ is sensible heat transfer from lake surface to atmosphere and can be expressed as $H=B \lambda E$, where $\mathrm{B}$ is the mean Bowen ratio for the period. Removing the two negligible terms, equation (7) is rewritten as: 


$$
E=\frac{R_{n e t}-S}{\lambda(1+B)}
$$

The interval-mean Bowen ratio $\mathrm{B}$ is calculated from daily Bowen ratios which are derived from air and lake surface temperatures $[7,10]$ as:

$$
B=\frac{\gamma}{n} \sum_{i=1}^{n} \frac{T_{s}-T_{a}}{e_{s s}-e_{s a}}
$$

Where, $\mathrm{e}_{\mathrm{ss}}$ is the saturated vapor pressure $(\mathrm{Pa})$ at Lake Surface and calculated by using the same Arden Buck [8] formula (mentioned before) by replacing water temperature $\left(\mathrm{T}_{\mathrm{s}}\right)$ instead of air temperature $\mathrm{T}_{\mathrm{a}}$.

\section{Comparison and Evaluation of Seven Methods}

The root mean square deviation (RMSD) is a frequentlyused measure of the differences between values predicted by an estimator and the values observed from the any thing being estimated. Another indication of how well the estimator follows/predicts the variations in the measured values could be given by a coefficient of efficiency (CE) as proposed and applied by Nash and Sutcliffe [17] and Yao [37]. This CE index is expressed as:

$$
C E=1-\frac{\sum\left(E_{\text {est }}-E_{\text {ref }}\right)^{2}}{\sum\left(E_{\text {ref }}-E_{\text {mean }}\right)^{2}}
$$

Where, $\mathrm{E}_{\text {est }}$ and $\mathrm{E}_{\text {ref }}$ are the estimated and reference (or measured) evaporation for an interval respectively, and $\mathrm{E}_{\text {mean }}$ is the mean of reference evaporations. A larger CE number indicates a more accurate estimator. Both indexes RMSD and $\mathrm{CE}$ are used in this study to evaluate and compare the accuracy and performance of the six evaporation methods, and a performance rank was then carried out.

\section{Results}

Results of reference evaporation calculation for 10 years (2003-2012) are presented first. They are followed by the results of evaporation estimated with the six methods. Then method comparison results are presented.

\subsection{Energy Budget}

Yearly mean values of meteorological variables are illustrated in Figures $2 \& 3$. Air temperature and Lake surface water temperature change in an identical way, as is usually expected. Air and water temperature have clear seasonal change, they decrease in winter and increase in summer. To their contrast, relative humidity does not have clear seasonal change, nor does wind speed have clear changes. Very little correspondence is seen between humidity or wind speed and temperature.

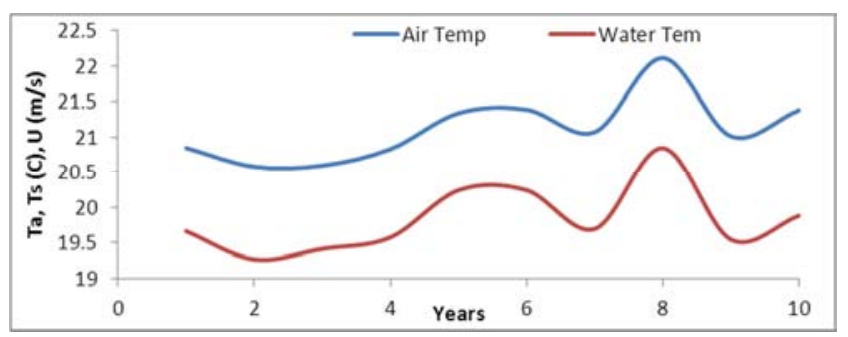

Figure 2. Yearly mean values of Air and water Temperature.

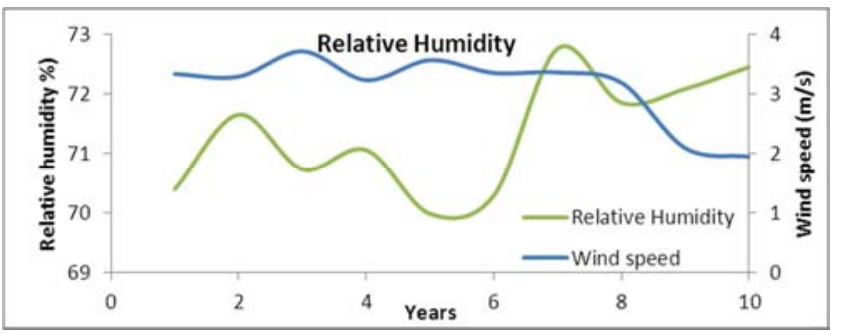

Figure 3. Yearly mean values of wind speed and humidity.

The total reference evaporation in 10 years, as calculated with the energy budget equations, fluctuates because of its natural changes with meteorological inputs. The evaporation rates for 120 months are representing in Figure 4a. The rate varies between 1.29-5.86 mm/d, with lower rates in January and December, and higher rates in June, July and August as shown in Figure 4b.
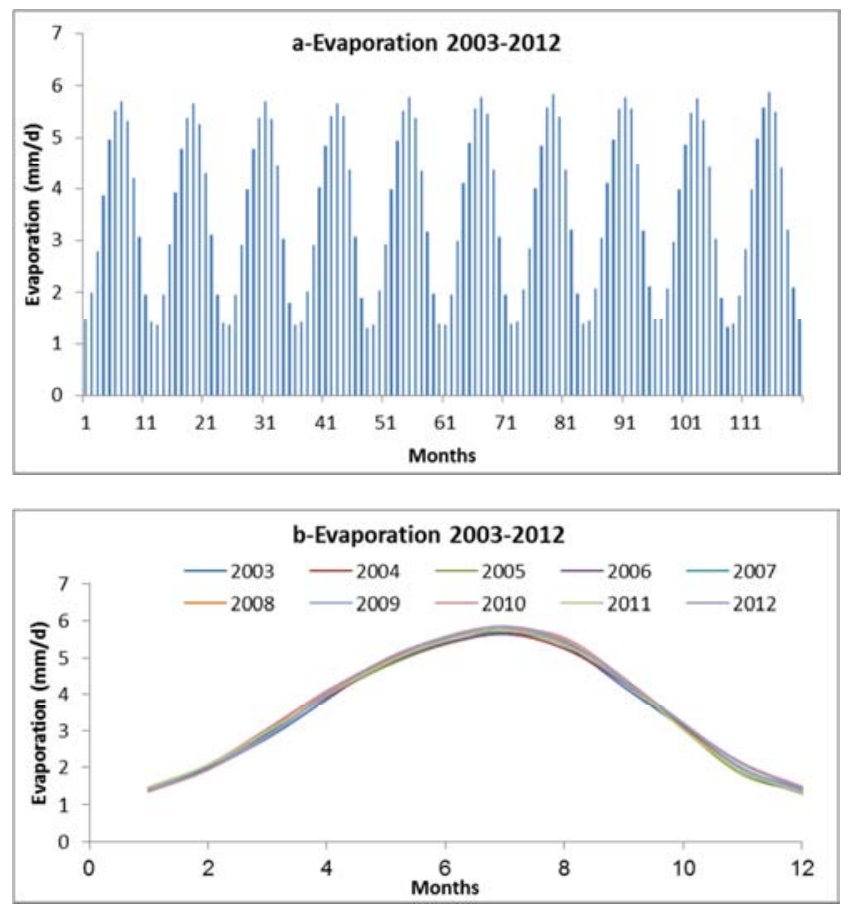

Figure 4. Monthly Mean values of reference evaporation rate $(\mathrm{mm} / \mathrm{d})$.

\subsection{Evaporation from Six Methods and Method Comparison}

Two examples of the results of evaporation obtained from the six methods are shown in Figures $5 \& 6$. Evaporation from Makkink and De Bruin-Kejimn are mostly close to reference 
evaporations, results of Jensin-Harise and Penman are away from the reference. Whereas results of Hamon even farther from the reference. Evaporation of the six methods have almost identical change pattern: low in winter and high in summer.

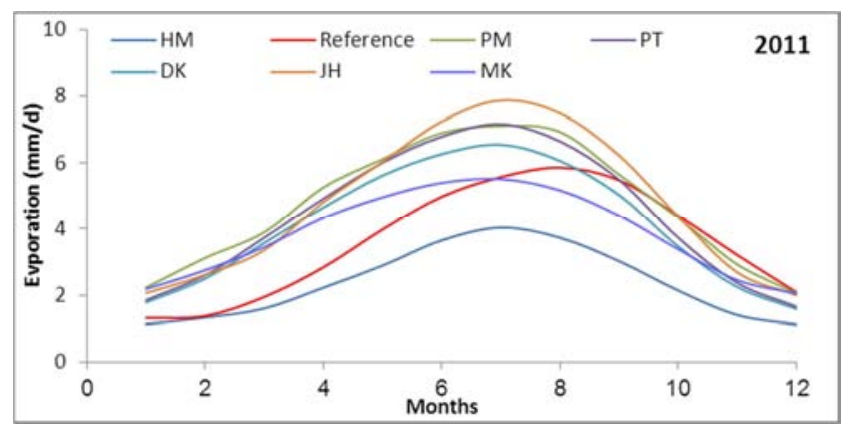

Figure 5. Comparison of six methods-estimated of evaporation with reference evaporation (mm/d) during 2011.

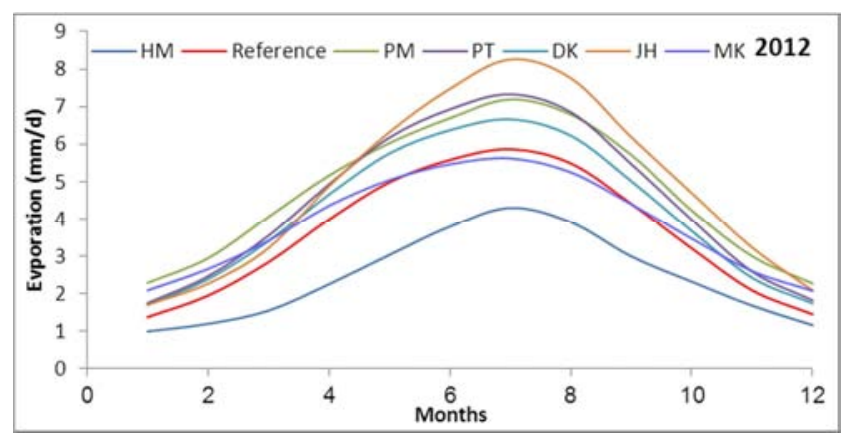

Figure 6. Comparison of six methods-estimated of evaporation with reference evaporation ( $\mathrm{mm} / \mathrm{d}$ ) during 2012.
Table 1 represents the evaporation results in $\mathrm{cm} /$ year of the study period (2003-2012) carried out using the previous water budget evaporation method in addition to the six methods. Table $2 \& 3$ represents the evaporation results of years 2011 and 2012 (for example) carried out using the previous six methods in addition to evaporation due to energy budget. The deviations $(\mathrm{mm} / \mathrm{d}$ ) (or error) of methods-estimated evaporation from the reference evaporation are shown in Figure 7. The MK deviations are scattered around the zero level (zero error level), with both positive and negative errors, being the best evenly scattered over the two years (2011 \& 2012). The HM deviations are scattered above the zero level (over estimated) for all two years. The DK, PT, PM and JH deviations are scattered below the zero level (under estimated) for all two years.

Table 4 represents the average, maximum and minimum for Lake Brullus evaporation during for the total period (2003-2012) in $\mathrm{mm} / \mathrm{d}$. Values of root mean squared deviation (RMSD) between estimated and reference evaporation, and values of coefficient of efficiency (CE) are listed in Table 5. A lower RMSD value or a higher CE value indicates a lower error between the estimated and reference evaporation. Therefore, a performance rank from best to least is determined by the RMSD and CE values, and the out put result rank is: MK, DK, PT, HM, JH and PM.

Table 1. Evaporation results (2003\&2012) carried out by using six different methods and reference evaporation (cm/year).

\begin{tabular}{|c|c|c|c|c|c|c|c|}
\hline Year/Method & HM & PM & PT & DK & JH & MK & Reference \\
\hline 2003 & 85.43 & 186.53 & 159.87 & 149.01 & 171.36 & 139.85 & 128.79 \\
\hline 2004 & 83.96 & 184.15 & 159.29 & 148.68 & 169.13 & 139.44 & 128.32 \\
\hline 2005 & 84.39 & 190.29 & 159.09 & 148.37 & 169.63 & 139.38 & 128.19 \\
\hline 2006 & 85.63 & 186.00 & 160.09 & 149.15 & 171.92 & 140.00 & 128.94 \\
\hline 2007 & 88.01 & 194.23 & 161.83 & 150.45 & 176.37 & 141.21 & 130.50 \\
\hline 2008 & 88.32 & 191.21 & 162.45 & 150.98 & 177.16 & 141.63 & 130.94 \\
\hline 2009 & 86.77 & 185.36 & 162.61 & 151.35 & 173.83 & 140.52 & 130.79 \\
\hline 2011 & 86.23 & 172.38 & 161.59 & 150.48 & 173.28 & 140.37 & 129.94 \\
\hline 2012 & 89.10 & 172.07 & 164.36 & 152.67 & 177.36 & 141.68 & 131.94 \\
\hline
\end{tabular}

Table 2. Evaporation results carried out by using six different methods and reference evaporation yearly mean and total evaporation (cm/year).

\begin{tabular}{lllllll}
\hline & HM & PM & PT & DK & JH & MK \\
\hline Average 2011 & 7.19 & 14.37 & 13.47 & 12.54 & 14.44 & 11.70 \\
Average 2012 & 7.42 & 14.34 & 13.70 & 12.72 & 14.78 & 11.81 \\
Total 2011 & 86.23 & 172.38 & 161.59 & 150.48 & 173.28 & 140.37 \\
Total 2012 & 89.10 & 172.07 & 164.36 & 152.67 & 177.36 & 14.93 \\
\hline
\end{tabular}

Table 3. Evaporation results (2011\&2012) carried out by using six different methods and reference evaporation (mm/d).

\begin{tabular}{|c|c|c|c|c|c|c|c|}
\hline Month/method & HМ & PM & PT & DK & JH & MK & Reference \\
\hline January-2011 & 1.13 & 2.23 & 1.85 & 1.78 & 2.06 & 2.18 & 1.47 \\
\hline 2 & 1.32 & 3.12 & 2.60 & 2.50 & 2.61 & 2.75 & 2.07 \\
\hline 3 & 1.60 & 3.90 & 3.73 & 3.58 & 3.36 & 3.45 & 2.98 \\
\hline 4 & 2.22 & 5.27 & 4.93 & 4.66 & 4.82 & 4.34 & 3.98 \\
\hline 5 & 2.89 & 6.12 & 6.01 & 5.63 & 6.04 & 4.97 & 4.87 \\
\hline 6 & 3.65 & 6.90 & 6.80 & 6.27 & 7.25 & 5.41 & 5.48 \\
\hline 7 & 4.04 & 7.12 & 7.17 & 6.55 & 7.88 & 5.52 & 5.76 \\
\hline 8 & 3.73 & 6.94 & 6.66 & 6.07 & 7.50 & 5.18 & 5.35 \\
\hline
\end{tabular}




\begin{tabular}{|c|c|c|c|c|c|c|c|}
\hline Month/method & HM & $\mathbf{P M}$ & PT & DK & JH & MK & Reference \\
\hline 9 & 3.02 & 5.66 & 5.50 & 5.04 & 6.24 & 4.41 & 4.42 \\
\hline 10 & 2.14 & 4.34 & 3.73 & 3.47 & 4.39 & 3.38 & 3.03 \\
\hline 11 & 1.40 & 2.93 & 2.37 & 2.25 & 2.69 & 2.45 & 1.91 \\
\hline 12 & 1.12 & 2.06 & 1.65 & 1.58 & 2.00 & 2.05 & 1.32 \\
\hline January-2012 & 0.99 & 2.28 & 1.75 & 1.70 & 1.70 & 2.09 & 1.37 \\
\hline 2 & 1.20 & 2.94 & 2.46 & 2.38 & 2.26 & 2.66 & 1.94 \\
\hline 3 & 1.55 & 4.06 & 3.55 & 3.40 & 3.21 & 3.41 & 2.84 \\
\hline 4 & 2.25 & 5.16 & 4.93 & 4.65 & 4.88 & 4.35 & 3.98 \\
\hline 5 & 3.03 & 6.03 & 6.17 & 5.75 & 6.32 & 5.04 & 4.98 \\
\hline 6 & 3.79 & 6.69 & 6.93 & 6.37 & 7.47 & 5.47 & 5.58 \\
\hline 7 & 4.30 & 7.19 & 7.33 & 6.66 & 8.26 & 5.62 & 5.87 \\
\hline 8 & 3.91 & 6.79 & 6.85 & 6.23 & 7.76 & 5.25 & 5.49 \\
\hline 9 & 2.99 & 5.72 & 5.47 & 5.01 & 6.19 & 4.40 & 4.41 \\
\hline 10 & 2.32 & 4.23 & 3.98 & 3.68 & 4.70 & 3.47 & 3.21 \\
\hline 11 & 1.68 & 3.00 & 2.59 & 2.42 & 3.23 & 2.60 & 2.09 \\
\hline 12 & 1.16 & 2.27 & 1.82 & 1.74 & 2.08 & 2.07 & 1.45 \\
\hline
\end{tabular}
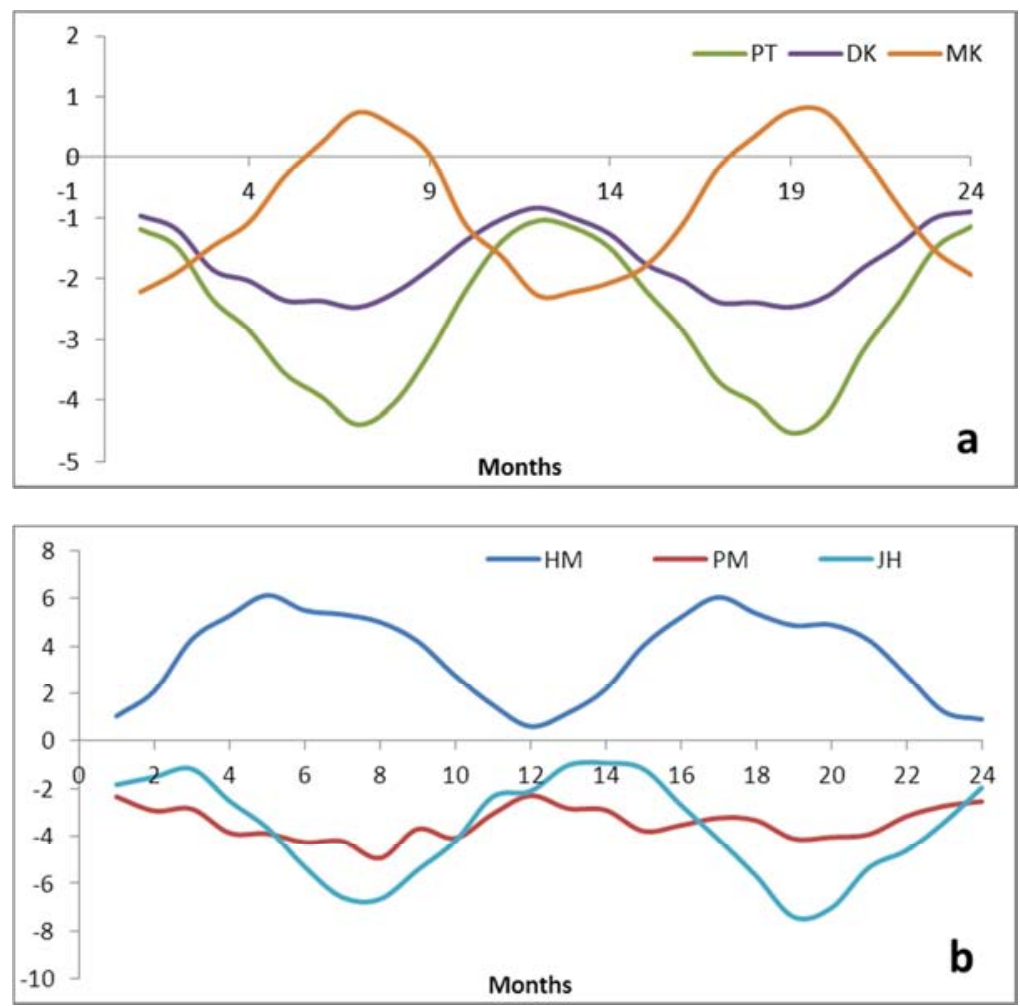

Figure 7. Deviation of estimated evaporation from reference evaporation (2011-2012) with (a) PT, DK, MK (b) HM, PM, JH and DB.

Table 4. Average, maximum, minimum, total and difference from reference evaporation method (mm/d) during the study period 2003 - 2012.

\begin{tabular}{llllllll}
\hline & HM & PM & PT & DK & JH & MK & Reference \\
\hline Average & 2.37 & 5.06 & 4.42 & 4.11 & 4.76 & 3.85 & 3.56 \\
Maximum & 4.30 & 8.06 & 7.33 & 6.66 & 8.26 & 5.62 & 5.87 \\
Minimum & 0.99 & 2.06 & 1.62 & 1.55 & 1.70 & 2.03 & 1.30 \\
Total & 284.68 & 607.47 & 530.09 & 493.47 & 570.95 & 461.55 & 426.84 \\
Difference & -142.16 & 180.63 & 103.25 & 66.63 & 144.11 & 34.72 & 0.00 \\
\hline
\end{tabular}

Table 5. RMSD and CE values of estimated vs. reference evaporations, and ranked performance of six evaporation methods when used to study period (2003-2012). The rank of six methods as appeared in Winter et al. [35]; Rosenberry et al. [21] and YAO [37] studies are also listed in this table for comparison.

\begin{tabular}{lllllll}
\hline Method & RMSD $\mathbf{~ m m}$ & CE & Rank & Rank by YAO [37] & Rank by Winter et al. [35] & Rank by Rosenberry [21] \\
\hline MK & 13.70 & 0.92 & 1 & 2 & 4 & 5 \\
DK & 17.86 & 0.86 & 2 & 3 & 3 & 3 \\
PT & 28.66 & 0.65 & 3 & 5 & 5 & 2 \\
HM & 40.60 & 0.30 & 4 & 6 & 6 & 6 \\
JH & 41.51 & 0.27 & 5 & 7 & 7 & 7 \\
PM & 47.20 & 0.05 & 6 & 4 & 2 & 4 \\
\hline
\end{tabular}




\section{Discussion}

The performance rank of the six methods recommended by Winter et al. [35], Rosenberry et al. [21] and YAO [37] are also listed in Table 5. It would be understandable that the all ranks may be different because the lakes are in different locations, and the datasets used are different YAO [37]. Makkink evaporation method being $1^{\text {st }}$ position of the present results rank against 2, 4, and 5 positions in YAO, Winter and Rosenberry ranks respectively. De-Bruin-Kejiman being $2^{\text {nd }}$ position of the present results and the $3^{\text {rd }}$ position among all other three ranks; Jensen-Haise is among those showing poorer results, positioned at $5^{\text {th }}$ of the present results and $7^{\text {th }}$ among all ranks.

In the following discussion try to interpret why the evaporation the ranked methods were fluctuated in their ranks as shown in Table 5. The first-ranked Makkink method has a simple empirical format and uses only air temperature and short-wave radiation as input YAO [37]. These two factors are the most important among many meteorological factors that have a significant effect on the evaporation mechanism in Egypt. Monthly estimates of evaporation using Makkini equation ranged from 2.03 to $5.62 \mathrm{~mm} / \mathrm{d}$ Table 4 . When compared with energy budget, the Makkink equation average underestimated evaporation of total period by as much as $0.15 \mathrm{~mm} / \mathrm{d}$ and average overestimated evaporation of total period by as much as $0.45 \mathrm{~mm} / \mathrm{d}$. During the study period (2003-2012), the total difference in evaporation estimation between the Makkink equation and the energy budget was $34.71 \mathrm{~mm}$ Table 4 .

The second-ranked DeBruin-Kejiman method it is also an empirical equation, like MK considers more affecting factors (temperature, short and long wave radiations, lake heat storage) than MK does. DeBruin-Kejiman equation determines evaporation rates as a function of the moisture content of the air above the water body, the heat stored in the lake, and the psychrometric constant, which is a function of atmospheric pressure and latent heat of vaporization YAO [37]. Monthly estimates of evaporation using the De-BruinKeijman equation ranged from 1.55 to $6.66 \mathrm{~mm} / \mathrm{d}$ Table 4 . When compared with the energy budget, the DeBruinKeijman equation overestimated evaporation by average of total period as $0.55 \mathrm{~mm} / \mathrm{d}$. During the study period, the total difference in evaporation estimation between the DeBruinKeijman equation and the energy budget was $66.63 \mathrm{~mm}$ Table 4.

The third-ranked Priestley-Taylor method is little bit good performance to calculate evaporation from Lake Brullus. Monthly estimates of evaporation by using the PriestlyTaylor equation range from 1.62 to $7.33 \mathrm{~mm} / \mathrm{d}$ Table 4, Monthly difference range of total period are overestimation by $0.86 \mathrm{~mm} / \mathrm{d}$. The total difference in evaporation estimation between the Priestly-Taylor equation and the energy budget of the total period was $103.25 \mathrm{~mm}$ Table 4 .

The fourth-ranked Hamon method give not bad evaporation estimates, in spite of it is only considers air temperature as the controlling factor.

\section{Conclusion}

A reference value of the evaporation from Lake Brullus was provided by a lake water energy budget, and was used to evaluate the performance of the six methods. The deviations of method carried out evaporation from reference evaporation were compared among the six methods, and an execution rank was suggested based on the comparison. Monthly evaporation rates were estimated for Lake Brullus in Northern Egypt and for the climatic conditions of the years $2003-2012$. The estimations of the energy budget consider the standard method, were compared to evaporation rates calculated with six other methods which are the Hamon, Penman, Priestley-Taylor, DeBruin-Kejiman, Jensen-Haise, and Makkink. The Makkink and DeBruin-Kejiman methods are the closest to the energy budget method. The Priestley-Taylor method shows an accepting result with respect to reference method, which though is poor for the Jensen-Haise and Penman methods. The mean rate of evaporation with the energy budget method for the study period (2003 and 2012) under investigation is 3.56 $\mathrm{mm} / \mathrm{d}$. The mean evaporation rate has been calculated with the other methods are: for the Hamon method, $2.37 \mathrm{~mm} / \mathrm{d}$, for Penman method, $5.06 \mathrm{~mm} / \mathrm{d}$, for Priestley-Taylor method, 4.42 $\mathrm{mm} / \mathrm{d}$, for DeBruin-Kejiman method, $4.11 \mathrm{~mm} / \mathrm{d}$, for JensenHaise method, $4.76 \mathrm{~mm} / \mathrm{d}$ and for Makkink method, 3.85 $\mathrm{mm} / \mathrm{d}$, respectively. The availability of climatic data is a main consideration in selecting an evaporation estimation method. The energy budget, Penman, Priestley-Taylor and Makkink methods are data intensive as they require measurement of many meteorological variables. The Hamon method is less data demanding.

\section{References}

[1] El-Adawy, A., Negm, A. M., Elzeir, M. A., Saavedra, O. C., El-Shinnawy, I. A., and Nadaoka, K. (2013). Modeling the hydrodynamics and salinity of El-Burullus Lake (Nile Delta, Northern Egypt). Journal of Clean Energy Technologies, 1 (2), 157-163.

[2] Alazrd, M., Leduc, C., Travi, Y., Boulet, G. \& Ben salem, A. (2015). Estimating evaporation in semi-arid areas facing data scarcity: Examples of the El Haouraeb dam (Merguellil catchment, Central Tunisia). Journal of Hydrology: Regional Studies, 3, 265-284.

[3] Al-Sodany, Y. A. (2009). Can the new recorded species be established in Brullus protected area: A Ramsar site in Egypt. African Journal of Agricultural Research, 4 (8), 752-764.

[4] Anderson, R. J. \& Smith, S. D. (1981). Evaporation coefficient for the sea surface from eddy flux. J. Geophysics Research, 86, 449-456.

[5] Anonymous, Climatic Normal for the Arab Republic of Egypt up to 1975. Ministry of Civil Aviation: Meteorological Authority. General Organization for Governmental Printing Offices, Cairo, 1980. 
[6] Assouline, S. \& Mahrer, Y. (1993). Evaporation from Lake Kinneret 1: Eddy correlation system measurements and energy budget estimates. Water Resources Research, 29, (4), 901-910.

[7] Assouline, S., Tyler, S. W., Tanny, J., Choen, S., Bou-Zeid, E., Parlange, M. B., \& Katul, G. G. (2008) Evaporation from three water bodies of different sizes and climate: Measurement and scaling analysis. Journal Advances in Water Resources, $31,160-172$.

[8] Buck, A. L. (1981) New equations for computing vapor pressure and enhancement factor. Journal of Applied Meteorology, 20, 1527-1532.

[9] Carter, D. B. (1956). The water balance of the Mediterranean and Black Seas. (Drexel Institute of technology, Laboratory of Climate). Climatology, Centerton, New Jersey, 11, 123-174.

[10] Chow, V. T., Maidment, D. R. \& Mays, L. W. (1988). Applied hydrology. McGraw-Hill Book Company, New York.

[11] Dos, J. R. \& Dias, N. L (1998). Multi seasonal lake evaporation energy budget estimates and CRLE model assessment with limited meteorological observations. Journal of Hydrology, 208, 135-147.

[12] De Bruin, H. A. R. \& Kejiman, J. Q. (1979). The PriestleyTaylor evaporation model applied to a large, shallow lake in the Netherlands. Journal of Applied Meteorology, 18, 898903.

[13] Doorenbus, J. \& Pruitt, W. O. (1977). Guidelines for predicting crop water requirements., Irrigation and Drainage Paper, Food and Agriculture Organization of the United Nations, Rome, Italy.

[14] Hussain, M. M. A., (1994). Remote sensing of some environmental conditions in Lake Brullus. Msc. Thesis, Alexandria University, p. 194, 1994.

[15] Lenters, J., Kratz, T. \& Bowser, C. (2005). Effects of climate variability on lake evaporation: Results from a long-term energy budget study of Sparkling Lake, northern Wisconsin (USA). Journal of Hydrology, 308, 168-195.

[16] Moazed, H., Ghaemii, A. A., \& Rafiee, M. R. (2014). Evaluation of several reference evapotranspiration methods: A comparative study of greenhouse and outdoor conditions. IJST, Transaction of Civil Engineering, 38 (C2): 421-437.

[17] Nash, J. E. \& Sutcliffe, J. V. (1970). River flow forecasting through conceptual models: Part I - a discussion of principle. Journal of Hydrology, 10, 282-290.

[18] Nilsen, I. N. (1912). Hydrgraphy of the Mediteranean and adjacent waters. Report of Danish Oceanographic Expedition in the Mediterranean (1908-1910), 1, 77-191.

[19] Paparrizos, S, Maris, F. \& Matzarakis, A. (2014). Estimation and comparison of potential evapotranspiration based on daily and monthly data from Sperchios Valley in Central Greece. Global NEST journal, 16 (2), 204-217.

[20] Patel, J. A., \& Majmundar, B. P. (2016). Development of evaporation estimation methods for a reservoir in Gujarat, India. American Water Works Association, 108 (9), E489E500.

[21] Rosenberry, D. O., Winter, T. C., Buso, D. C. \& Likens, G. E.
(2007) Comparison of 15 evaporation methods applied to a small mountain lake in the northeastern USA. Journal of Hydrology, 340, 149-166.

[22] Sacks, L., Lee, T. \& Radell, M. (1994). Comparison of energy budget evaporation losses from two morphometrically different Florida seepage lakes. Journal of Hydrology, 156, 311-334.

[23] Said, M. A. (1993). Evaporation from the Mediterranean shelf waters off the Egyptian coast. Mahssaga, 26 (1), 1-7.

[24] Said, M. A. \& Hussein, M. M. A. (2013) Estimation of evaporation from Lake Burullus (Egypt) using different techniques. Journal of King Abdel Aziz University: Marine Science, 24 (1), 55-67.

[25] Said, M. A. Shakweer, L. M. \& Radwan, A. (2005). Water and nutrient budget of lake Borullus. Journal of Egyptian German Society of Zoology, 48 (A), 1-15.

[26] Schott, G. (1915). Die Gewasser des Mittelmeeres. Annual journal of Hydrography and Marine Meterology, 43 (1-18), 49-79.

[27] Souch, C., Wolfe, C. P., Susan, C. \& Grimmond, B. (1996). Wetland evaporation and energy partitioning: Indiana Dunes National Lakeshore. Journal of Hydrology, 184, 189-208.

[28] Sturrock, A., Winter, T. \& Rosenberry, D. (1992). Energy budget evaporation from Williams Lake: A closed lake in north central Minnesota. Water Resources research, 28 (6), 1605-1617.

[29] Sverdrup, H. U. (1942). The Oceans. Prentice-Hall, no. 4, $1087 \mathrm{pp}, 1942$.

[30] Tixeront, I. (1970). Le billan hydrologique de la Mer Noire et de la Mer Mediterranee., Cah. Oceanography, 22, 227-237.

[31] Valiantzas, J. D. (2006). Simplified version for the Penman evaporation equation using routine weather data. Journal of Hydrology, 331, 690-702.

[32] Vardavas, I. M. (1987). Modeling the seasonal radiation of net all-wave radiation flux and evaporation in a tropical wet-dry region", Ecological Modeling, 39, 247-268.

[33] Vardvas, I. M. \& Fountoulakis, A. (1996). Estimation of lake evaporation from standard meteorological measurements: application to four Australian lakes in different climatic regions. Ecological Modeling, 84, 139-150.

[34] Winter, T., Buso, D., Rosenberry, D., Likens, G., Sturrock, A. Jr. \& Mau, D. (2003). Evaporation determined by the energybudget method for Mirror Lake, New Hampshire. Limnology and Oceanography, 48 (3), pp. 995-1009, 2003.

[35] Winter, T. C., Rosenberry, D. O. \& Sturrock, A. M. (1995). Evaluation of 11 equations for determining evaporation for a small lake in the north central United States. Water Resources Research, 31, 983-993.

[36] Wust, G. (1959). Sulle componenti del bilancio idrio fra atmosfera oceans e Mediterranco", Ann. Institute, University of Naval, Napoli, 28, 371-386.

[37] Yao, H. (2009). Long-term study of lake evaporation and evaluation of seven estimation methods: results from Dickie Lake south-central Ontario, Canada. Journal of Water Resource and Protection, 2, 59-77. 
[38] Yao, H. \& Creed, I. F. (2005). Determining spatiallydistributed annual water balances for un-gauged locations on Shikoku Island, Japan: a comparison of two interpolators. Hydrological Sciences Journal, 50, 245-263.
[39] Yao, H., Terakawa, A. \& Chen, S. (1996). Rice water use and response to potential climate changes: calculation and application to Jianghan, China, in Proceedings of the International Conference on Water Resources and Environment Research, Kyoto, Japan, 2, 611-618. 